\title{
Humane use of animals
}

SIR - The selection of Peter Singer as reviewer for Monkey Business and In the Name of Science ${ }^{1}$ serves neither the purpose of objectivity nor intellectual criticism. Monkey Business is a partisan account of the explosive events that put People for the Ethical Treatment of Animals (PETA) on the map. As a reviewer of this book, Singer provides no balance: he is of the same philosophical bent as the book's author and is widely recognized as the intellectual father of the current animal rights movement. Although most of your readers are probably aware of the Silver Spring monkeys case, few of them are likely to have more than a sketchy recollection of the hotly contested charges and counter-charges that the case involving Edward Taub has engendered during the past decade. Singer's review adds clarity to neither Monkey Business nor the debate.

Singer selectively rehashes a few disputed facts in the case but neglects even to mention the affiliation of the author, Kathy Snow Guillermo, with PETA and glosses over the huge financial benefits PETA has reaped by utilizing the hapless primates as bait for a decade of direct-mail fund-raising. He simply uses the credibility granted to him as a book reviewer for Nature to enshrine through repetition a distorted version of the case. He is entitled to his opinions, but Nature surely owes its readers a better analysis than he provided.

Singer states that Taub was prosecuted for animal cruelty by the state of Maryland in connection with his alleged treatment of the 17 monkeys under his supervision at the Institute for Behavioral Research. He notes that Taub was convicted of only a single count of the more than a hundred initial charges, and that this guilty finding was set aside later on the "scarcely reassuring ground that Maryland animal protection laws did not apply to experimenters receiving federal grants". The Maryland Court of Appeals may have decided the Taub case on the issue of jurisdiction, but its reasoning vindicated Taub on two grounds: his research (which addressed problems of stroke rehabilitation by creating in monkeys a comparable loss of sensory perception) fell within the state statute's exemption for "normal human activities to which the infliction of pain to an animal is purely incidental and unavoidable" and, as federally funded research with regulated species, it was already subject to multiple federal regulations concerning humane animal care and use.

Singer also misses the mark in his review of In the Name of Science when he suggests that the "animal research industry oppose[s] every attempt by the animal rights movement to achieve the most moderate gains in animal welfare". The undersigned members of the scientific community have engaged in cooperative efforts with many animal welfare groups. The scientific community has sought to improve laboratory animal care. Scientists participated in the development of the US Animal Welfare Act regulations, and we are involved in efforts to ensure adequate funding for the US Department of Agriculture's Animal and Plant Health Inspection Service, which enforces those regulations.

In the United States, the constructive dialogue between the research community and moderate animal welfare groups has produced regulations that ensure that research animals are humanely treated as they contribute to the development of treatments to alleviate suffering of animals and humans alike. But it must at the same time be recognized that it is impossible for researchers to find common ground with the most extreme organizations and individuals, whose goal is the abolition of animal use in research, rather than the improvement of laboratory animal care.

\section{William H. Dantzler}

(President, American Physiological Society, 9650 Rockville Pike, Bethesda, Maryland

20814-3991, USA); Larry R. Squire

(President, Society for Neuroscience);

Robert G. Petersdorf (President,

Association of American Medical Colleges); Joel G. Hardman (President, American

Society for Pharmacology and Experimental Therapeutics); David Johnson (Executive

Director, Federation of Behavioral,

Psychological and Cognitive Sciences, representing 18 national societies).

SIR - Singer ${ }^{1}$ perpetuates an extremely misleading view of the legal outcome of the accusations against Taub. And a fact that became available only after the second trial - namely that an acute infection that led to amputation of one monkey's arm was acquired well after the monkey was taken from Taub's laboratory - makes it a virtual certaintly that Taub would have been factually acquitted on this final charge if the case had not been dismissed on the basis that Singer noted.

In furthering the appearance that Taub neglected his animals, Singer ignores important evidence that the court found compelling. It was documented, for example, that in the period immediately before the raid on Taub's laboratory, an animal caretaker had been absent from the laboratory on only one day in more than a year. Significantly, an animal caretaker was present at the laboratory every day of Taub's previous vacation. Practices during the period near the time of the raid, however, departed markedly from this pattern. (Taub was on vacation for the 15 days immediately before the raid.) Two caretakers had been assigned to care for the animals during Taub's absence. The two were to alternate duty each day. During the 15 days before the police raid, which was instigated by PETA, the caretakers were absent a total of seven days. They were absent for three consecutive days before antivivisection visitors were secretly brought to the laboratory by the PETA member who under false pretences had gained a job in the laboratory. They were absent for the three days before and including the day of the police raid, and for one additional day as well.

As the caretakers testified to different excuses for each absence, the probability of the foregoing occurring by chance is less than one in several million. It was such evidence that led to the court's acquittal of Taub.

Referring to Taub's surgery, Singer asserts that "officials at NIH were later to admit that the fractures, dislocations, lacerations, punctures, contusions, abrasions with accompanying infections, acute and chronic inflammation and necrosis are not the inevitable consequences of deafferentation". The assertion to which Singer refers appears to have been made in a published discussion of the case in the Neuroscience Newsletter (Fall 1983 Vol. 14 Part 5 p. 7). Singer did not point out that the NIH veterinarians making the assertion had no previous experience in the treatment of deafferented monkeys. He also did not mention that their assertion was vigorously disputed in the newsletter by the neuroscience veterinarians who investigated Taub and who had prior experience in the treatment of such monkeys.

Finally, Singer writes that "perhaps the most disturbing aspect of the case is the way the US scientific community rallied to support Taub. On the evidence produced in court, there can be little doubt that, legal technicalities aside, and whatever one thinks of the nature and value of the research itself, Taub failed to provide basic veterinary care to the monkeys in his laboratory."

His assertion is in striking contrast to the outcomes of the trials and the final opinion of the US Public Health Service Grant Appeals Board. After its investigation, that board did uphold the termination of Taub's grant on technicalities. The board pointedly did not say, however, that any of these technicalities involved harm to the monkeys. This is what the board concluded: "In summary, the record does not support a conclusion that the monkeys actually were harmed by the lack of regular veterinary supervision, or that the condition of the monkeys showed inadequate veterinary care". Why should anyone find it disturbing that, after independently considering the same facts, the 